\title{
Current knowledge on use of essential oils as alternative treatment against fish parasites
}

\author{
Marcos Tavares-Dias* \\ Embrapa Amapá, Rodovia Juscelino Kubitschek, km 5, 2600, 68903-419 Macapá, AP, Brazil
}

Received 22 June 2017 / Accepted 10 January 2018

Handling Editor: Ryan B. Carnegie

\begin{abstract}
This review article focuses on current knowledge about in vitro and in vivo experimentation relating to use of essential oils (EOs) to combat fish parasites. In addition, we discuss the existing methodologies used in studies to determine the antiparasitic activity of EOs, along with their toxicity and major compounds. The methodological approaches used to describe the anthelmintic properties of EOs were demonstrated. The consistency of their activity and thus their potential use for fish ectoparasites (in vitro and in vivo) and endoparasites (in vitro) control was reviewed. There is a clear need to find EOs and active agents of EOs to treatment in vivo against endoparasites of fish. Thus, progress may be achieved through considering the beneficial aspects of EOs when their complementarity and potentiality are exploited. EOs are therefore viable alternative sources of therapeutic products against fish parasites. On the other hand, use of chemotherapeutics has been increasingly questioned, such that constant environmental and consumer concerns regarding them now exist. The synergistic functions of EOs, in comparison with the action of one or two major compounds of these oils, seems unquestionable. It is possible that their activity is modulated by several molecules of the major compounds. Lastly, EOs are bioactive products that are viable sources of therapy against fish parasites. Although more than 3000 EOs are known, less than $0.4 \%$ of them have been tested on fish parasites. Thus, it has become clear that more studies testing these therapeutic alternatives are required, in order to evaluate the antiparasitic potential of other EOs for controlling fish parasites and to maximize their benefits to hosts.
\end{abstract}

Keywords: Aquaculture / fish / parasites / essential oils / toxicity / treatment

\section{Introduction}

Aquaculture is a fast growing activity on all continents, at a rate of around $7 \%$ per year, accounting for more than half of the fish used in human consumption (Engle, 2016; FAO, 2016; Engle et al., 2017). Aquaculture is therefore an important source of food, nutrition, income and livelihood for hundreds of millions of people around the world. In 2014, the world production from aquaculture was 73.8 million tons, with an estimated value of more than US\$ 160 billion. Of this total, 49.8 million tons $(67.5 \%)$ were fish, with a value of US\$ 99.2 billion (FAO, 2016).

Freshwater fish farming contributes more than two-thirds of the world's aquaculture production (Bastos Gomes et al., 2017). Its growth has been influenced by the increase in world demand for foods of protein origin and for white meat, as well as by the high market value of different fish species. Moreover,

*Corresponding author: marcos.tavares@embrapa.br freshwater fish farming is an excellent alternative for minimizing the intense wild fish exploitation that occurs in diverse regions of the planet. In addition, current growth of the global population has been leading to additional expansion of intensive fish production, because of demand for food (Engle et al., 2017; Soler-Jiménez et al., 2017).

In fish farming, fish populations are undergoing continuous selection to improve the economic efficiency of this animal production. However, a number of both external and internal factors affect fish production, and these problems unequivocally include parasitosis (Soler-Jiménez et al., 2017). High stocking density and the handling practices used in fish farming are among the factors involved. The increasing prevalence of fish farming has led to increased occurrence of parasitic diseases that compromise the sustainability of the fish farming industry (Soler-Jiménez et al., 2017; Soares et al., $2017 \mathrm{a}, \mathrm{b})$. The diseases cause mortality, slow growth of fish and reduction of feed conversion rates, and they decrease the commercial value of fish (Bastos Gomes et al., 2017). Globally, it has been estimated that diseases cause economic 
losses to fish farming of around US\$ 1-US\$ 10 billion/year (Shinn et al., 2015). Therefore, there is a constant need for improvements in disease prevention among farmed fish, to avoid such losses of production.

Spreading and establishment of parasites may have detrimental health consequences for farmed fish when these parasites are present at high abundance. Thus, knowledge of the potential risks that parasites represent to farmed fish has been needed, along with knowledge of the appropriate contingency measures and management strategies for parasitic infections. In fish farming, diseases are generally treated by means of chemical substances (e.g. formalin, sodium chloride, acetic acid, potassium permanganate, copper sulfate, praziquantel, parathion, levamisole, fenbendazole, ivermectin, emamectin benzoate, diflubenzuron, etc.). However, their use can cause problems such as selection of resistant organisms, aggression to the environment and to humans because of the accumulation of chemical residues. Thus, consumption of farmed fish that have been treated may present risks to health (Ling et al., 2015; Hashimoto et al., 2016; Soares et al., 2016; Soares et al., 2017a, b). Therefore, use of chemical pesticides to control fish diseases is often restricted in many countries (Ling et al., 2015). In addition, use of conventional anthelmintic treatments seems to potentially have high cost. It is important to recognize that, although parasitic infections occur at the level of the individual, their impact is on the population as a whole, and the response must therefore be at the level of the community, not the individual. Such problems have stimulated investigation of the use of medicinal plants as an alternative for treating parasitic diseases in farmed fish (Soares and Tavares-Dias, 2013; Hashimoto et al., 2016; Soares et al., 2017a, b), based on the large numbers of bioactive components presented by these plants (Bakkali et al., 2008; Soares and Tavares-Dias, 2013; Sharifi-Rad et al., 2017).

Recently, the use of medicinal plants or their bioactive compounds, for controlling diseases that compromise the production and productivity of fish of interest for farming, has been increasing. Herbal therapy is a potentially beneficial alternative for fish farming, since it may be cheaper and more effective than chemotherapy (Soares and Tavares-Dias, 2013; Soares et al., 2016; Soares et al., 2017a, b). Globally, advances in disease management may result in increased economic sustainability, improved livelihoods for producers and greater contribution of fish farming to the local, regional and national economies (Engle et al., 2017), as well as providing natural treatment that is more efficient. Use of chemotherapeutics needs to be reduced and replaced by other effective measures for diminishing disease outbreaks (Engle et al., 2017). A recent review on the potential of plant extracts as a sustainable and effective substitute for chemical treatments showed that there are increasing numbers of studies highlighting the potential application of natural products and plants extracts to fish (Reverter et al., 2014), including essential oils (EOs). Thus, given the diversity of EOs, their application to fish farming has been investigated worldwide. Such studies are of great importance and interest, given that better knowledge of plant species that produce EOs could contribute towards use of these phytotherapeutics for treating parasitic infections within fish farming. This issue has not been well addressed globally, in comparison with use of plant extracts.
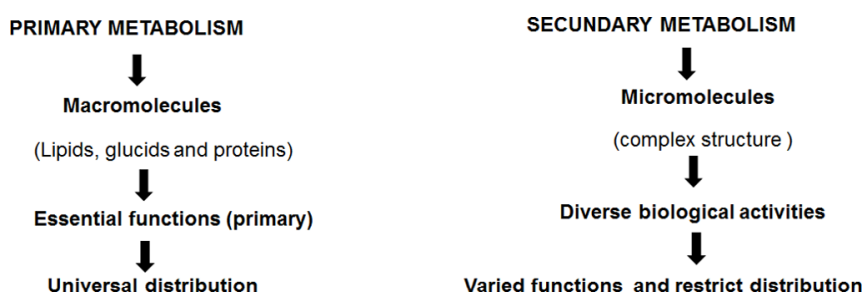

Fig. 1. Differentiation of primary and secondary metabolism of the plants (Poser and Mentz, 2010).

The present article had the aim of reviewing the potential of EOs from plants, focusing on their pivotal role as a source of bioactive phytochemicals against fish parasites. Thus, special emphasis was placed on reporting and discussing the use of EOs within fish parasitology, using in vitro and in vivo treatment systems. In order to make this review article as exhaustive as possible, a review was performed by searching databases (SciELO, ISI, Scopus, Science Direct, BioOne, Gale, Highwire Press, SpringerLink, Zoological Records, $\mathrm{CAB}$ Abstracts databases and Google Scholar). Several database cross-researches were conducted using the keywords "EO and parasite and fish". A total of 113 articles were found and 62 were selected for this review, once they had relation with $\mathrm{EO}$ and fish or EO and parasites and fish. Here, we report and discuss the results that matched our criteria.

\section{Secondary metabolites of plants and essential oils}

Plants contain products from primary and secondary metabolisms (Fig. 1) that are of great importance for their existence. The secondary metabolism of plants contributes towards their colonization of terrestrial environments. Secondary metabolites relate plants to their ecosystem, because the pigments and aromatic compounds that confer color and aroma to their reproductive organs and fruits attract pollinators and favor dispersion of seeds by the animals involved. In addition, volatile compounds among the secondary metabolites can repel phytophagous organisms, including viruses and phytoplasma vectors, while phytoalexins are broad-spectrum antimicrobial metabolites (Bakkali et al., 2008; Poser and Mentz, 2010; Sharifi-Rad et al., 2017). The origin of these secondary metabolites from glucose are summarized in Figure 2. These bioactive compounds are synthesized through alternative cellular metabolism pathways involving shikimic acid and amino acids, and they are stored in compartments, cell vacuoles or trichomes, depending on their chemical nature (for more details, see Santos, 2010). Thus, diverse bioactive substances can be produced at the same time and at different parts of a plant, which are directed to the different stimuli that have been experienced. Secondary metabolites can be produced in various parts of the plant (leaves, stems, roots, flowers and seeds) and their concentrations are affected by the plant species, its stage of development, seasonality, climatic and geographical conditions and extraction method (Soares and Tavares-Dias, 2013; Schelkle et al., 2015; Cunha et al., 2016, Sharifi-Rad et al., 2017).

EOs have been used for over 5000 years for a variety of purposes, including personal care (perfumes and cosmetics), 


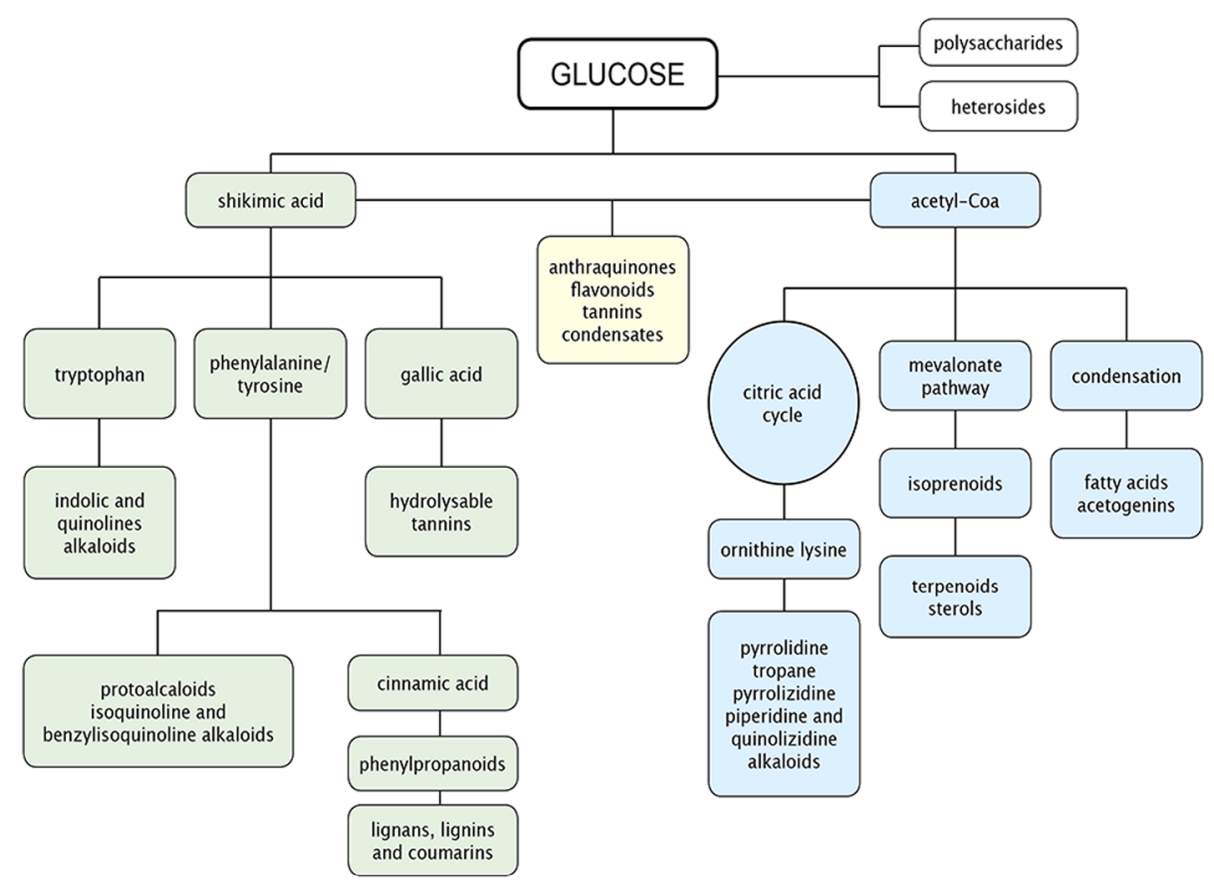

Fig. 2. Biosynthesis cycle of the secondary metabolites of medicinal plants (Santos, 2010).

food, home care, repellents for humans, livestock and domestic animals, and as health-promoting agents for treating various diseases in humans and animals (Bakkali et al., 2008; Raut and Karuppayil, 2014; Sharifi-Rad et al., 2017). Use of plants for treating diseases (phytotherapy) has always been a common practice among indigenous tribes worldwide, and this continues today. The knowledge thus generated was incorporated into the daily life of these populations and became part of their cultural heritage. It remained active through verbal transmission of knowledge between different generations. However, with increasing regional integration between these traditional communities and modern communities, a process of incorporation of this cultural practice began. However, as in any process of cultural fusion, losses and additions of knowledge have occurred. Recently, demand for EOs from medicinal plants has increased considerably because of the search for new bioactive products with potential antiparasitic activity for different animal species of interest for farming, including fish.

EOs are volatile complex mixtures of numerous compounds obtained from medicinal plants and generally contain more than 20 different low molecular weight components at varying concentrations. They are characterized by having a very diverse composition, mainly terpenes (hydrocarbons) such as myrcene, pinene, terpinene, limonene, $\mathrm{p}$ - cymene, $\alpha$ and $\beta$-phellandrene, etc.; and terpenoids (oxygen-containing hydrocarbons) such as acyclic monoterpene alcohols (geraniol or linalool), monocyclic alcohols (menthol, 4-carvomenthenol, terpineol, carveol or borneol), aliphatic aldehydes (citral, citronellal or perillaldehyde), aromatic phenols (carvacrol, thymol, safrole or eugenol), bicyclic alcohol (verbenol), monocyclic ketones (menthone, pulegone or carvone), bicyclic monoterpenic ketones (thujone, verbenone or fenchone), acids (citronellic acid or cinnamic acid) and esters (linalyl acetate). Some EOs may also contain oxides (1,8-cineole), sulfurcontaining constituents, methyl anthranilate, coumarins and sesquiterpenes such as zingiberene, curcumin, farnesol, sesquiphellandrene, turmerone, nerolidol, etc. (Bakkali et al., 2008; Santos, 2010; Sharifi-Rad et al., 2017). Many of these bioactive molecules are found at low concentrations (less than $1 \%$ ), while a few of them are major compounds that can represent up to $70 \%$ of the total volume of oil and are mainly responsible for the bioactive effects of the EO (Bakkali et al., 2008; Cunha et al., 2017). Several of these secondary metabolites of medicinal plants present diverse antiparasitic activity (Bakkali et al., 2008; Soares and Tavares-Dias, 2013; Romero et al., 2014, Valero et al., 2015; Hashimoto et al., 2016, Soares et al., 2016; Sharifi-Rad et al., 2017).

Currently, more than 3000 EOs are known, but only around one-tenth of these are of importance for use in the pharmaceutical, nutritional or cosmetic industries (SharifiRad et al., 2017), or in veterinary medicine (Soares and Tavares-Dias, 2013; Sharifi-Rad et al., 2017). Considering the great global diversity of medicinal plant species and the possibility of cultivating them, as well as the commercial and industrial interest in EOs, this number is expected to increase considerably. Use of EOs has been widely disseminated over recent years, since many of them have antibacterial, antioxidant, antifungal, analgesic, anticancer, insecticide, spasmolytic, carminative, hepatoprotective, growth-promoting and cytotoxic activities (Soares and Tavares-Dias, 2013; Raut and Karuppayil, 2014; Sharifi-Rad et al., 2017), as well as activity against endoparasites and ectoparasites of animals and humans that are resistant to conventional drugs (Sharifi-Rad et al., 2017). Use of EOs may be an alternative for increasing profits in fish farming and reducing the use of conventional antiparasitic agents. However, the antiparasitic activity of EOs can vary according to differences in their chemical composition, which influence what their major compounds are (Soares and Tavares-Dias, 2013; Sharifi-Rad et al., 2017) and consequently their antiparasitic activity. 
Table 1. Toxicity of different essential oils and its major compounds for different fish species.

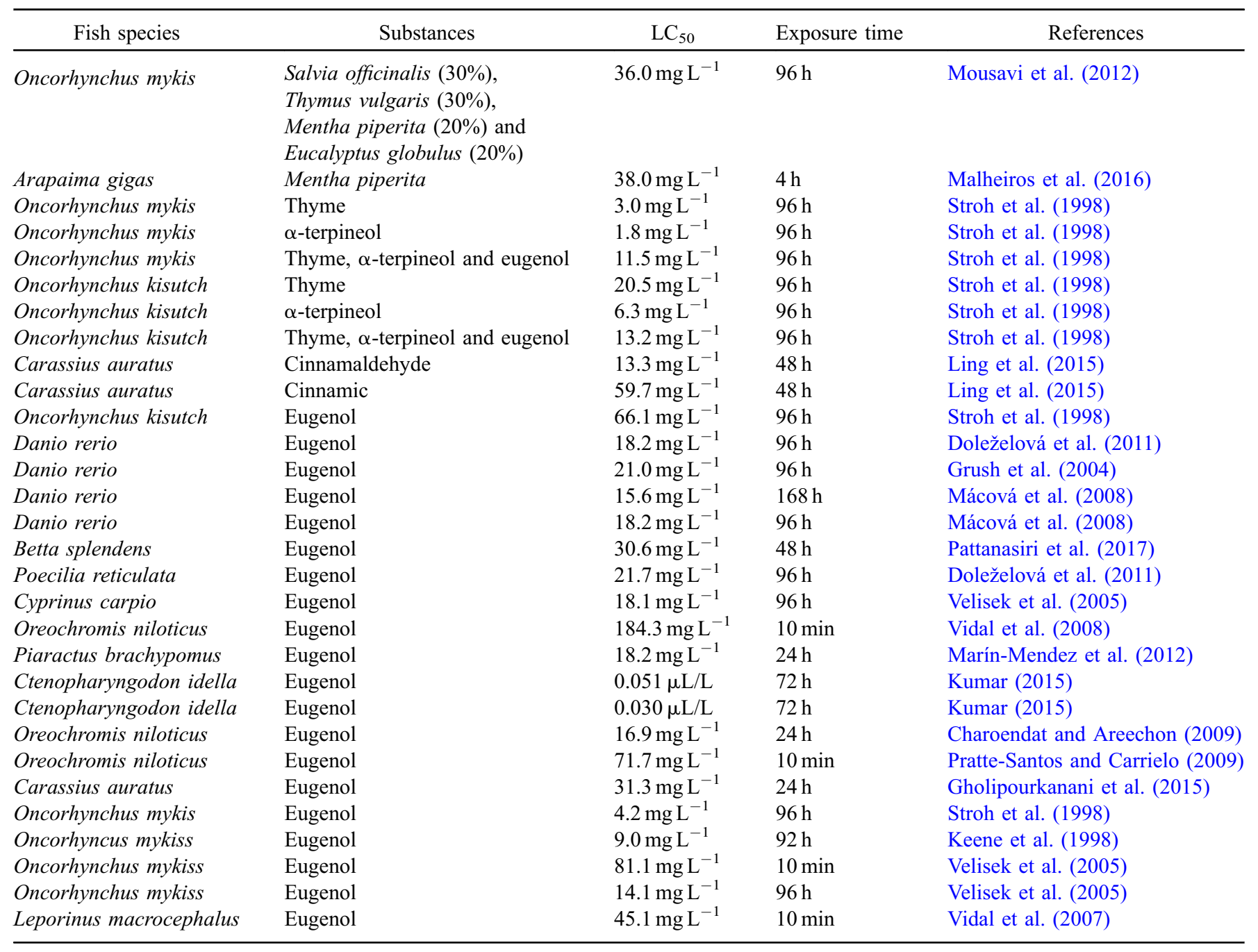

\section{Toxicity of essential oils and their major compounds in fish}

The toxicity of a particular substance is its property of potentially establishing a pathological state when introduced to an organism or interacting with it. In relation to fish, this can be verified through toxicological evaluation, by obtaining data such as concentration, clinical signs and induced adverse effects. Toxicological evaluations using the EO concentrations tested for the desired fish species can be performed as acute, sub-chronic or chronic evaluations for $24-96 \mathrm{~h}$. Such toxicity tests should be previously performed to assess the toxic and adverse effects of EOs or their major compounds on each species of fish. The levels at which toxic effects are observed, identification and characterization of the organs affected, severity of effects after repeated exposure and reversion of toxic effects should be determined. The administration route should be the one intended for use or likely exposure. Such assays determine safe limits for use of EOs or their major compounds, since the therapeutic concentration may be near or above the lethal concentration (LC) for the fish. One of the criteria that EOs should meet is their safety for use on fish at treatment concentrations. The recommended treatment concentrations vary according to fish species and size, exposure time, bath quality and temperature (Doleželová et al., 2011; Malheiros et al., 2016).

Like any therapeutic drug, EOs can also have adverse or toxic side effects. The toxicity of a few EOs and some of their major compounds has been investigated for a variety of fish species, especially eugenol (4-allyl-2-methoxyphenol$\mathrm{C}_{10} \mathrm{H}_{12} \mathrm{O}_{2}$ ), which present toxicity towards different fish species. Thus, the LC of eugenol for the fish assayed ranged from 1.8 to $184.3 \mathrm{mg} \mathrm{L}^{-1}$, and it was influenced by the exposure time and fish species (Tab. 1). Eugenol is the main component of several aromatic plants with antiparasitic activity (see Raja et al., 2015) and is of interest for fish farming, primarily because of its anesthetic action (Sutili et al., 2014; Boijink et al., 2015), for reducing stress and preventing mechanical damage to fish during handling. In addition, currently, eugenol is used for controlling fish parasites because of its anthelminthic effects (Boijink et al., 2015).

Cunha et al. (2016) reported that the mortality rate among silver catfish Rhamdia quelen was $10 \%$ after $96 \mathrm{~h}$ of exposure to Tagetes minuta EO at $50 \mathrm{mg} \mathrm{L}^{-1}, 70 \%$ and $80 \%$ after $24 \mathrm{~h}$ 
and $96 \mathrm{~h}$, respectively, at $100 \mathrm{mg} \mathrm{L}^{-1}$, and 80,90 and $100 \%$ after 24, 48 and $96 \mathrm{~h}$, respectively, at $200 \mathrm{mg} \mathrm{L}^{-1}$; and in $R$. quelen exposed to EOs of Cunila galioides and Origanum majorana at $100 \mu \mathrm{LL}^{-1}$, there was $100 \%$ mortality after $2 \mathrm{~h}$ (Cunha et al., 2017). Fingerlings of Oreochromis niloticus presented $100 \%$ mortality when exposed (30 or $60 \mathrm{~min}$ ) to $1000,500,250$ and $125 \mu \mathrm{g} / \mathrm{mL}$ of a commercial garlic EO, Allium sativum (Hussein et al., 2013). For Gambusia affinis, exposure to $500 \mathrm{mg} \mathrm{L}^{-1}$ of Corymbia citriodora EO caused $100 \%$ mortality after $10 \mathrm{~min}$ (Escartin and Mariani, 2014). In O. niloticus, eugenol at $286.5 \mathrm{mg} \mathrm{L}^{-1}$ caused $100 \%$ mortality (Vidal et al., 2008). A study on Piaractus mesopotamicus reported that almost $50 \%$ of the fish did not survive exposure to Melaleuca alternifolia (Valladão et al., 2016). In addition, mortality among Brycon hilarii exposed to eugenol at $250 \mathrm{mg} \mathrm{L}^{-1}$ (Fabiani et al., 2013), hybrid P. mesopotamicus $x$ Piaractus brachypomus exposed to $50 \mathrm{mg} \mathrm{L}^{-1}$ (Rodrigues et al., 2015), Centropomus undecimalis exposed to $75 \mathrm{mg} \mathrm{L}^{-1}$ (Bernardes-Júnior et al., 2013) and Cyprinus carpio exposed to $0.08 \mathrm{mg} \mathrm{L}^{-1}$ (Kamble et al., 2014) has been reported.

Several studies on EOs have also used biochemical, hematological and histopathological parameters to evaluate signs of toxicity in the oil tested (Hashimoto et al., 2016; Soares et al., 2016; Soares et al., 2017a, b). Malheiros et al. (2016) investigated the toxicity of Mentha piperita $\left(20^{-1} 60\right.$ $\mathrm{mg} \mathrm{L}^{-1}$ ) towards Arapaima gigas and found alterations on the gills such as epithelial elevations, secondary lamella fusion, hypertrophy and aneurysm, but necrosis occurred only when $160 \mathrm{mg} \mathrm{L}^{-1}$ of $M$. piperita was used.

Consequently, it has often proven impossible to use the best concentrations that were obtained from in vitro tests on EOs, in therapeutic baths for fish, due to toxicity (Malheiros et al., 2016; Hashimoto et al., 2016; Valladão et al., 2016; Soares et al., 2016; Soares et al., 2017a, b). Therefore, there is always a need to know the sublethal concentrations of each EO for each fish species to be treated. Accurate prior information regarding the safety margin for each EO ensures success in relation to survival of the treated fish. The concentration and duration of exposure of these natural products are not specific for each species and size (age) of the fish, or for parasite species.

\section{In vitro activity of essential oils on fish parasites}

Validation of EOs is an initial obligatory step for correct use of these therapeutic substances and their major compounds. This stage is characterized by in vitro tests that allow recognition of the existence of the antiparasitic properties of the EO that is being investigated. At the same time, chemical characterization of EOs needs to be undertaken to identify their bioactive compounds. Therefore, in searching for usable EOs with antiparasitic activity, in vitro assays are fundamental for making a preliminary analysis on the major compounds and their action. Among the main advantages of using in vitro studies to test the antiparasitic properties of EOs are their low cost, their quick results and the possibility of broad screening. Moreover, there is no need for experimentation on vertebrates. It should be emphasized that differences in sensitivity between methodologies for evaluating the antiparasitic activity of EOs in vitro may occur. Such differences may be due to the technical limitations of the methodologies as well as the antiparasitic potential of a certain EO towards the species of parasites.

In vitro studies using different EOs have shown promising results relating to parasite control in fish, especially against monogeneans. The efficacy against different species of monogeneans has ranged from 60 to $100 \%$ (Tab. 2), and against nematodes from 0 to $100 \%$ (Valero et al., 2015). In this article, studies on in vitro use of EOs and their major compounds against Anisakis simplex published up to 2014 were not used, since there is an excellent review conducted recently by Valero et al. (2015). These authors reviewed the in vitro efficacy of Cuminum cyminum, Cymbopogon citratus, Cymbopogon martinii, Cymbopogon winterianus, Litsea cubeba, Pelargonium graveolens, Origanum vulgare, Matricaria chamomilla, M. piperita, Myristica fragans and Piper nigrum on $A$. simplex, along with more than 30 major compounds.

Most of the in vitro studies on the effects of EOs or their compounds have been directed to A. simplex (Valero et al., 2015), a nematode that can cause zoonosis in humans (Hierro et al., 2004; Romero et al., 2014; Giarratana et al., 2015; Valero et al., 2015; Pérez et al., 2016), along with monogeneans (Tab. 2 ), which are helminths ectoparasites that cause great economic losses in fish farming due to epizootics (Steverding et al., 2005; Soler-Jiménez et al., 2017). Other parasitic helminth species has been neglected as causative agents of farmed fish diseases, because fish farmers have often believed that these parasites are harmless. However, at high abundance, some endohelminth species may harm fish production and productivity.

Cytotoxic properties are of great importance in applications of EOs, not only against certain pathogens that have been widely reported (Bakkali et al., 2008; Maryam et al., 2015; Sharifi-Rad et al., 2017), but also in relation to different parasites (Novato et al., 2015, Valladão et al., 2016). EOs have a very close interaction with the phospholipids of cell membranes due to the short extent of their carbon chains and high hydrophobicity of their constituents (Maryam et al., 2015). Because of the great number of constituents, EOs seem to have no specific cellular targets. As typical lipophiles, they pass through the cell wall and cytoplasmic membrane, disrupt the structure of different layers of polysaccharides, fatty acids and phospholipids and permeabilize these layers (Bakkali et al., 2008; Maryam et al., 2015, Sharifi-Rad et al., 2017).

Studies using histological analysis showed damage to the cuticle and gastrointestinal tract of nematodes in fish exposed to the EO of Thymus vulgaris (Giarratana et al., 2014) and Rlimonene (Giarratana et al., 2015), and to the EO of Cymbopogon sp. (Justino and Barros, 2008) and geraniol, citronellol, citral, carvacrol and cuminaldehyde (Hierro et al., 2004). However, for monogeneans in fish, the mechanisms of action of EOs and their major compounds are little known. In Dactylogyrus intermedius exposed to cinnamaldehyde from Cinnamomum cassia, monogeneans covered with deep wrinkles were observed. The tegument was extensively damaged due to perforation caused by these majority compounds (Ling et al., 2015). Moreover, it is suspected that the presence of oxygenated compounds is partially involved in this action in monogeneans (Steverding et al., 2005). 
Table 2. In vitro efficacy of different essential oils and their major compounds for different fish species.

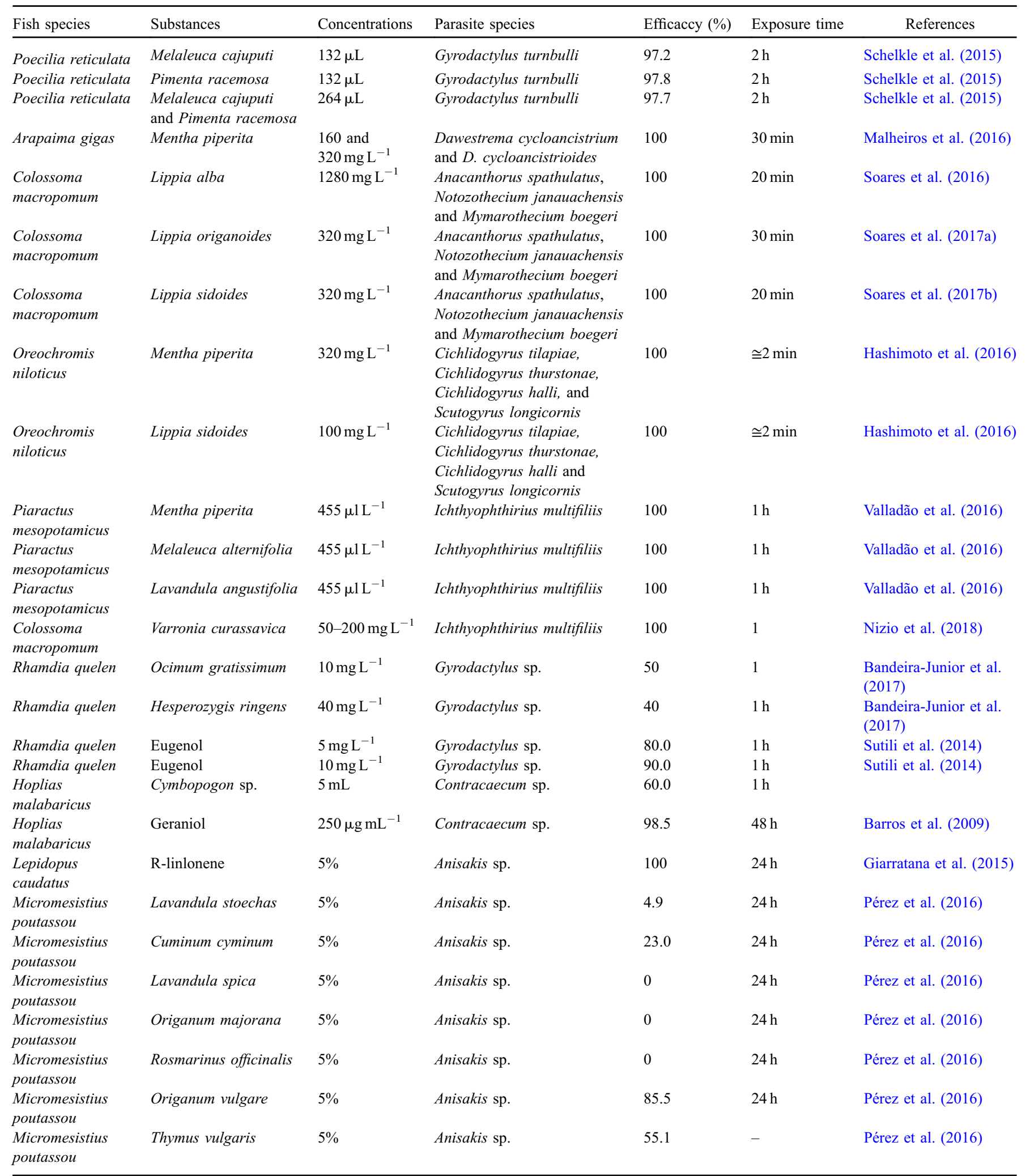


Table 3. In vivo efficacy of different essential oils and their major compounds for different fish species.

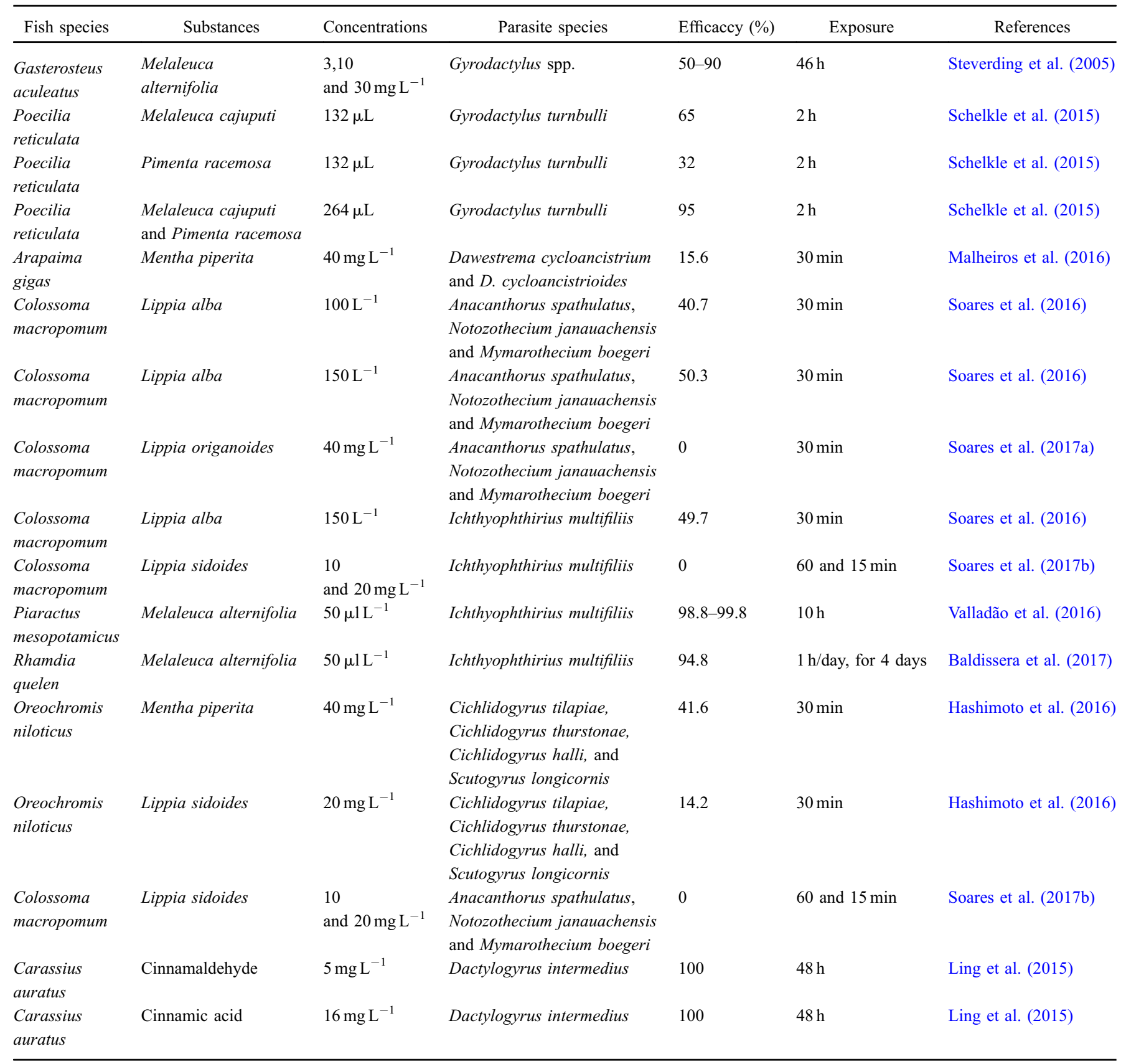

\section{In vivo activity of essential oils in fish parasites}

After screening for the in vitro effects and toxicity of EOs, tests using therapeutic baths are conducted, because in searching for products with antiparasitic activity, the efficacy of these products is fundamental in determining whether they can be used in fish farming. These therapeutic interventions can be done in a variety of ways, but both prolonged baths (hours to days) and short-duration baths (minutes to hours) using the desired EO are often used to treat fish that are infested with ectoparasites such as monogeneans.
Several EOs have been tested as phytotherapeutic antiparasitic agents against different species of monogeneans and Ichthyophthirius multifiliis in fish, with efficacies ranging from 0 to $100 \%$, depending on the EO and the therapeutic strategy used (Tab. 3). When short-terms baths have been repeated over a three to five-day period, greater efficacy has been observed.

In vivo assays on larvae of $A$. simplex showed that $\mathrm{LD}_{50}$ EOs ranged from 9.5 to $46.9 \mathrm{mg}$ in a carrier of $0.5 \mathrm{~mL}$ of olive oil caused the dead of all larvae in the gastric cavity of rats (Valero et al., 2015). However, studies in vivo with EOs has been not performed with regard to larvae of Anisakis or other 
endoparasite species in fish. Therefore, there are lack of studies on treatment in vivo with EOs against endoparasites of fish. Using an in vivo test, Ling et al. (2015) reported that the median effective concentrations $\left(\mathrm{EC}_{50-48 \mathrm{~h}}\right)$ of cinnamaldehyde and cinnamic acid in EOs of $C$. cassia against monogeneans $D$. intermedius in Carassius auratus were $0.57 \mathrm{mg} \mathrm{L}^{-1}$ and $6.32 \mathrm{mg} \mathrm{L}^{-1}$, respectively. In view of the fact that, in the trials carried out in vitro and in vivo for different helminths ectoparasites, the different EOs and its compounds tested had promising results for use in aquaculture. Therefore, we can conclude that these products represent a good starting point in the search for an effective drug to treat endoparasitosis in fish.

Studies on EOs of Lippia alba, Lippia sidoides and Lippia origanoides against monogeneans in Colossoma macropomum showed that these had low efficacy because it was only possible to use low concentrations in therapeutic baths. In these studies, signs of stress were indicated by the hematological changes observed. In addition, severe lesions such as lamellar epithelium hyperplasia and fusion, capillary dilatation, epithelial detachment and lamellar aneurysm, epithelial rupture with hemorrhage, congestion, edema and necrosis, proliferation of mucosal cells and chloride cells and lamellar hypertrophy were reported in the gills of fish exposed to these EOs (Soares et al., 2016; Soares et al., 2017a, b).

Since EOs do not readily dissolve in water, diluents such as absolute alcohol, Tween 80 and dimethyl sulfoxide are commonly used as solvents. These also exhibit some antiparasitic activity, although it is low (Steverding et al., 2005; Hashimoto et al., 2016; Soares et al., 2016; Soares et al., 2017a, b).

Finally, it has become clear that approaches that use alternative therapeutics, such as EOs, coupled with improvements in water quality and fish health conditions may bring about reductions in parasite load within fish production. Thus, we propose that a holistic approach is required in relation to evaluating the potential of EOs for fish parasite control and for maximizing their benefits for hosts.

\section{Total essential oil: is its use the way forward for validation against fish parasites?}

Regarding the biological properties of EOs, it has to be borne in mind that these are complex mixtures of numerous molecules. It might be wondered whether their biological effects result from synergism among all the molecules or whether they reflect action only by the main molecules that are present at the highest levels (Bakkali et al., 2008). Synergistic effects occur when two compounds increase each other's potency, thus resulting in mixtures that have stronger effects than would be predicted based on the activity of their components in isolation. Synergistic effects are especially useful in clinical situations. Through reducing the dose required to achieve a medicinal effect, selectively synergistic drug combinations can both reduce costs and lower the risk of fish toxicity. The synergistic effects of complex mixtures are thought to be important in plant defenses against herbivore insects. Plants usually present defenses as a suite of compounds, not as individual ones, and it is thought that the minor constituents may act as synergists, thereby enhancing the effect of the major compounds through a variety of mechanisms. Thus, it has frequently been noted that EOs are considerably more efficacious than the compounds derived from them (Pavela, 2010). Synergistic interactions between the constituents of EOs have been also reported in several areas of scientific research (Novato et al., 2015; Tak and Isman, 2015). It was found that an association between thymol and carvacrol had moderate synergetic effects against Amblyomma sculptum larvae, while thymol in combination with carvacrol had a synergetic effect against Dermacentor nitens larvae. An association between carvacrol and (E)cinnamaldehyde had an antagonistic effect against $D$. nitens and A. sculptum. The magnitude of the effects of the major compounds was only dependent on their concentration when they were tested alone or as part of EOs (Bakkali et al., 2008).

Screening of EOs has become increasingly important in the search for viable alternatives against fish parasites, with the expectation that individual major compounds may have antiparasitic properties that, when combined, act synergistically such that parasites will be hyper-susceptible. Melaleuca cajuputi EO, which is dominated by 1,8-cineole, co-occurs with limonene; thus, the combination of these constituents may cause antagonistic, synergistic or additive anthelmintic interactions, depending on their ratio and on the limonene enantiomer present (Schelkle et al., 2015). Thus, the major compounds seem to very well reflect the biophysical and biological features of the EOs that have been analyzed.

Studies using carvacrol, alpha-pinene and beta-pinene showed that these major compounds of various EOs have anthelmintic activity against the nematode Anisakis spp. (Hierro et al., 2004; Navarro et al., 2008). These results relating to synergic activity of these substances were later confirmed by Giarratana et al. (2014) using oil from sunflower seeds (T. vulgaris), which presents these three components. Therefore, it seems unquestionable that synergistic effects between the various molecules contained in an EO, in comparison with the action of one or two main components of this EO, do exist. Nonetheless, it is possible that other minor molecules may modulate the activity of the main components. Moreover, it is likely that several components of the EOs play a role in cell penetration, in lipophilic or hydrophilic attraction and fixation on cell walls and membranes, and in cellular distribution. This last feature is very important because the distribution of the oil in the cell determines the different types of radical reactions produced, which depend on their compartmentation in the cell. In this regard, for biological purposes, it is more informative to study an entire oil rather than some of its components, because the concept of synergism appears to be more meaningful (Bakkali et al., 2008).

The strength of the synergistic effects of total EO varies between plants and types of assay. Thus, the antiparasitic effects of the EO will depend on both the presence of major compounds and the parasite species. The presence of synergistic compound combinations in a total EO may therefore augment the antiparasitic activity of these natural products. Therefore, synergistic interactions, in which the total EO is more effective than a single major compound, are of particular clinical, veterinary and ecological interest, given that synergistic combinations of total EOs may have greater efficacy against fish parasites or achieve clinical effects at a 
lower dosage, which may reduce the risk of toxicity for the host fish.

\section{Conclusions and perspectives}

It does not come as a surprise that, in fish aquaculture, parasitic infections have serious deleterious effects that result in significant loss of yield, and hence of profit, just as they do in relation to animal husbandry. For this reason, we emphasize the need to consider alternative treatment methods that use bioactive products from medicinal plants, such as EOs. Some EOs suitable for treating parasitic helminths in fish do exist, especially for treating monogeneans and nematodes. Contrary to expectations, very few EOs have been subjected to controlled experimentation to demonstrate their anthelmintic activity, either through in vitro assays or through therapeutic baths (in vivo assays) for parasitized hosts. However, increasing numbers of controlled experimental studies are being conducted with the aims of verifying and quantifying such activity. Regarding the in vitro and in vitro specificity of different EOs and major compounds, the studies analyzed here determined that anthelmintic specificity to different oils exists. Considering the large number of known EOs (more than 3000), the issue of specificity remain unanswered for most EOs. However, we consider that it would be sensible to look for evidence regarding whether EOs might diminish the effects of parasites on the host fish population, and on their wellbeing and production levels. Furthermore, indicators of the sustainability of anthelmintic activity of EOs should be ascertained before incorporating them in plans for fish parasite control.

Despite the anthelmintic properties of EOs, it remains unclear whether EOs could actually have a role in controlling parasitism directly in fish farming, because no validation has been carried out. These bioactive products and major compounds have also been correlated with toxic effects on hosts, which leads to use of low concentrations with varying efficacy. Thus, we recommend that threshold points should be established, below which the efficacy of EOs for fish parasite control should not be considered. We also suggest that such threshold points should be around 70\% (Soares et al., 2017b).

The global community recognizes that alternative methods for dealing with some of the commonest infections in fish farming do exist. However, the lessons from the past have much to impart, and recent studies have strengthened the evidence regarding the need for ecologically friendly tools, to make parasite control programs feasible within fish farming. Thus, the challenge is to make it happen. Experience with other forms of animal husbandry has shown over the years that antiparasitic drug resistance has occurred whenever intensive control measures have been used. As a result, most of the effective conventional anthelmintics have been rendered useless. Therefore, in fish farming, use of chemotherapeutants will decline with the use of herbal products, including EOs, and they will be replaced by gradually increased use of these natural substances and other prophylactic measures to reduce disease outbreaks. Furthermore, because of the volatility and low molecular weight of EO constituents, EOs are often quickly eliminated from the fish body through metabolic pathways (Cunha et al., 2016).
Finally, the low water solubility of EOs is an issue that remains unresolved. It has been considered to be a major disadvantage in relation to fish farming, since it hinders making these compounds available in water. Nanoemulsions offer several benefits, including sustained release, increased absorption rate and therapeutic potency and reduced toxicity and drug concentration (Bajerski et al., 2016). They may also improve the low water solubility of EOs and their major compounds. Furthermore, the enhanced activity of EOs through nanoencapsulation (Maryam et al., 2015), which may be tested for EO treatments on fish parasites, can be highlighted. Thus, nanotechnology can be used to overcome such constraints, but there is still a need to investigate such technologies with EOs, in treatments for fish parasites.

Acknowledgements. To the National Council for Scientific and Technological Development (CNPq, Brazil) for a research fellowship (\# 303013/2015-0).

\section{References}

Bajerski L, Michels LR, Colomé LM, Bender EA, Freddo RJ, Bruxel F, Haas SE. 2016. The use of Brazilian vegetable oils in nanoemulsions: an update on preparation and biological applications. Braz J Pharm Sci 52: 347-363.

Bakkali F, Averbeck S, Averbeck D, Idaomar M. 2008. Biological effects of essential oils. A review. Food Chem Toxicol 46: 446475.

Baldissera MD, Souza CF, Moreira KLS, Rocha MIUM, Veiga ML, Baldisserotto B. 2017. Melaleuca alternifolia essential oil prevents oxidative stress and ameliorates the antioxidant system in the liver of silver catfish (Rhamdia quelen) naturally infected with Ichthyophthirius multifiliis. Aquaculture 480: 11-16.

Bandeira-Junior G, Pês TS, Saccol EMH, Sutili FJ, Rossi-Junior W, Murari AL, Heinzmann BM, Pavanato MA, Vargas AC, Silva LL, Baldisserotto B. 2017. Potential uses of Ocimum gratissimum and Hesperozygis ringensessential oils in aquaculture. Ind Crops Prod 7: 484-491.

Barros LA, Yamanaka AR, Silva LE, Vanzeler MLA, Braum DT, Bona J. 2009. In vitro larvicidal activity of geraniol and citronellal against Contracaecum sp. (Nematoda: Anisakidae). Braz J Med Biol Res 42: 918-920.

Bastos Gomes G, Jerry DR, Miller TL, Hutson KS. 2017. Current status of parasitic ciliates Chilodonella spp. (Phyllopharyngea: Chilodonellidae) in freshwater fish aquaculture. J Fish Dis 40: 703-715.

Bernardes-Júnior JJ, Nakagome FK, Mello GL, Garcia S, AmaralJúnior H. 2013. Eugenol as an anesthetic for juvenile common snook. Pesqui Agropecu Bras 48: 1140-1144.

Boijink CL, Miranda WSC, Chagas EC, Dairiki JK, Inoue LAKA. 2015. Anthelmintic activity of eugenol in tambaquis with monogenean gill infection. Aquaculture 438: 138-140.

Charoendat U, Areechon N. 2009. Efficacy of synthetic eugenol as an anesthetic for Nile Tilapia (Oreochromis niloticus Linn.). Kasetsart J (Nat Sci) 43:132-140.

Cunha JA, Scheeren CA, Oliveira AM, Sutili FJ, Pinheiro CG, Baldisserotto B, Heinzmann BM. 2016. Toxicity of Tagetes minuta essential oil in silver catfish (Rhamdia quelen). Int J Pharm Pharm Sci 8: 286-288.

Cunha JA, Scheeren CA, Salbego J, Gressler LT, Madaloz LM, Junior GB, Bianchini AE, Pinheiro CG, Bordignon SAL, Heinzmann BM, Baldisserotto B. 2017. Essential oils of Cunila galioides and 
Origanum majorana as anesthetics for Rhamdia quelen: efficacy and effects on ventilation and ionoregulation. Neotrop Ichthyol 15: e160076. DOI:10.1590/1982-0224-20160076.

Doleželová P, Mácová S, Plhalová L, Pištěková V, Svobodová Z. 2011. The acute toxicity of clove oil to fish Danio rerio and Poecilia reticulata. Acta Vet Brno 80: 305-308.

Engle RC. (2016). Transforming the journal of world aquaculture society in support of global aquaculture. J World Aquac Soc 47: 35.

Engle RC, D'Abramo L, Ponniah AG, Slater M. 2017. Global aquaculture 2050. J World Aquac Soc 48: 3-6.

Escartin S, Mariani S. 2014. Evaluating the toxicity of oil of lemon eucalyptus, Corymbia citriodora (Hook.), against larvae of the Asian tiger mosquito and non-target fish and larval amphibians. Anal Biol 36: 97-105.

Fabiani BM, Boscolo WR, Feiden A, Diemer O, Bittencourt F, Neu DH. 2013. Benzocaine and eugenol as anesthetics for Brycon hilarii. Acta Sci Anim Sci 35: 113-117.

FAO. 2016. The state of world fisheries and aquaculture 2016. Contributing to food security and nutrition for all. Food and Agriculture Organization of the United Nations, Rome, Italy.

Gholipourkanani H, Gholinasab-Omran I, Ebrahimi P, Jafaryan H. 2015. Anesthetic effect of clove oil loaded on lecithin based nanoemulsions in gold fish, Carassius auratus. J Fish Aquat Sci 10: $553-561$.

Giarratana F, Muscolino D, Beninati C, Giuffrida A, Panebianco A. 2014. Activity of Thymus vulgaris essential oil against Anisakis larvae. Exp Parasitol 142: 7-10.

Giarratana F, Muscolino D, Panebianco F, Patania A, Beninati C, Ziino G, Giuffrida A. 2015. Activity of $\mathrm{R}(+)$ limonene against Anisakis larvae. Ital J Food Saf 4: 209-211.

Grush J, Noakes DLG, Moccia RD. 2004. The efficacy of clove oil as an anesthetic for the zebrafish, Danio rerio (Hamilton). Zebrafish 1: 46-56.

Hashimoto GSO, Marinho Neto F, Ruiz ML, Acchile M, Chagas EC, Chaves FCM, Martins ML. 2016. Essential oils of Lippia sidoides and Mentha piperita against monogenean parasites and their influence on the hematology of Nile tilapia. Aquaculture 450: 182-186.

Hierro I, Valero A, Pérez P, González P, Cabo MM, Montilla MP, Navarro MC. 2004. In vivo larvicidal activity of monoterpenic derivatives from aromatic plants against L3 larvae of Anisakis simplex s.1. Phytomedicine 11: 77-82.

Hussein MMAH, Hassan WH, Moussa IMI. 2013. Potential use of allicin (garlic, Allium sativum Linn, essential oil) against fish pathogenic bacteria and its safety for monosex Nile tilapia (Oreochromis niloticus). J Food Agricul Environ 11: 696-699.

Justino CHS, Barros LA. 2008. In vitro evaluation of the resistance of the Contracaecum sp. larvae (Railliet and Henry, 1912) (Nematoda: Anisakidae), to the essential oil of citronella (Cymbopogon sp.) (Poaceae). Rev Bras Cienc Vet 15: 122-125.

Kamble AD, Saini VP, Ojha ML. 2014. The efficacy of clove oil as anesthetic in common carp (Cyprinus carpio) and its potential metabolism reducing capacity. Int J Fauna Biol Stud 1: 1-6.

Keene JL, Noakes DLG, Moccia RD, Soto CG. 1998. The efficacy of clove oil as an anaesthetic for rainbow trout, Oncorhynchus mykiss (Walbaum). Aquac Res 29: 89-101.

Kumar P. 2015. Annesthetic effects of clove oil on survivility of grass carp, Ctenopharyngodon Idella carp seed. The Bioscan 10: 11391144.

Ling F, Jiang C, Liu G, Li M, Wang G. 2015. Anthelmintic efficacy of cinnamaldehyde and cinnamic acid from cortex cinnamon essential oil against Dactylogyrus intermedius. Parasitology 142: $1744-1750$.

Mácová $\mathrm{S}$, Doleželová $\mathrm{P}$, Pištěková $\mathrm{V}$, Svobodová Z, Bedánová I, Vosláŕová E. 2008. Comparison of acute toxicity of 2phenoxyethanol and clove oil to juvenile and embryonic stages of Danio rerio. Neuroendocrinol Lett 29: 680-684.

Malheiros DF, Maciel PO, Videira MN, Tavares-Dias M. 2016. Toxicity of the essential oil of Mentha piperita in Arapaima gigas (pirarucu) and antiparasitic effects on Dawestrema spp. (Monogenea). Aquaculture 45: 81-86.

Marín-Mendez GA, Torres-Cortes A, Naranjo-Suarez L, ChacónNovoa RA, Rondón-Barragan IS. 2012. Lethal (96hLC50) concentration of eugenol in the Red-bellied Pacu (Piaractus brachypomus). Orinoquia 16: 62-66.

Maryam I, Huzaifa U, Hindatu H, Zubaida S. 2015. Nanoencapsulation of essential oils with enhanced antimicrobial activity: a new way of combating antimicrobial resistance. $J$ Pharmacogn Phytochem 4: 165-170.

Mousavi SM, Mirzargar SS, Mousavi HE, Omidbaigi R, Khosravi A, Bahonar A. 2012. Antifungal and toxicity effects of new combined essential oils on Oncorhynchus mykiss in comparison with malachite green. Iranian J Vet Sci Technol 4: 1-8.

Navarro MC, Noguera MA, Romero MC, Montilla MP, González de Selgas JM, Valero A. 2008. Anisakis simplex s.1.: larvicidal activity of various monoterpenic derivatives of natural origin against L3 larvae in vitro and in vivo. Exp Parasitol 120: 295-299.

Nizio DAC, Fujimoto RY, Maria AN, Carneiro PCF, França CCS, Sousa NC, Brito FA, Sampaio TS, Arrigoni-Blank MF, Blank AF. 2018. Essential oils of Varronia curassavica accessions have different activity against white spot disease in freshwater fish. Parasitol Res 117: 97-105.

Novato TPL, Araújo LX, Monteiro CMO, Maturano R, Senra TOS, Matos RS, Gomes GA, Carvalho MG, Daemon E. 2015. Evaluation of the combined effect of thymol, carvacrol and (E) cinnamaldehyde on Amblyomma sculptum (Acari: ixodidae) and Dermacentor nitens (Acari: ixodidae) larvae. Vet Parasitol 212: 331-335.

Pattanasiri T, Taparhudee W, Suppakul P. 2017. Acute toxicity and anaesthetic effect of clove oil and eugenol on Siamese fighting fish, Betta splendens. Aquac Int 25: 163-175.

Pavela R. 2010. Acute and synergistic effects of monoterpenoid essential oil compounds on the larvae of Spodoptera littoralis. $J$ Biopestic 3: 573-578.

Pérez MGM, Moll CN, Espinosa GM, López AV. 2016. Evaluation of different Mediterranean essential oils as prophylactic agents in anisakidosis. Pharm Biol 55: 456-461.

Poser GL, Mentz LA. Diversidade biológica e sistema de classificação, in: C.M.O. Simões, E.P. Schenkel, G. Gosmann, J.C.P. Mello, P.R. Petrovick (orgs.). Farmacognosia: da planta ao medicamento. Editora UFRGS: Porto Alegre, Editora UFSC, Florianópolis, 2010, pp. 75-89.

Pratte-Santos R, Carrielo FAD. 2009. Toxicidade aguda de eugenol em juvenis de tilápia (Oreochromis niloticus). Rev Cient Faminas 5: 95-104.

Raja MRC, Srinivasan V, Selvaraj S, Mahapatra SK. 2015. Versatile and synergistic potential of eugenol: a review. Pharm Anal Acta 6: 367. DOI:10.4172/21532435.1000367.

Raut JS, Karuppayil SM. 2014. A status review on the medicinal properties of essential oils. Ind Crops Prod 62: 250-264.

Reverter M, Bontemps N, Lecchini D, Banaigs B, Sasal P. 2014. Use of plant extracts in fish aquaculture as an alternative to 
chemotherapy: current status and future perspectives. Aquaculture 433: 50-61.

Rodrigues RB, Melo IWA, Rocha JDM, Silva TC, Bridi VRC, Feiden A, Bittencourt F, Boscolo WR. 2015. Eugenol como anestésico para alevinos de patinga (Piaractus mesopotamicus x Piaractus brachypomus). Rev Bras Hig Sanid Anim 9: 634-644.

Romero MC, Navarro MC, Sanchez JM, Valero A. 2014. Peppermint (Mentha piperita) and albendazole against anisakiasis in an animal model. Trop Med Int Health 19: 1430-1436.

Santos RI. Metabolismo básico e origem dos metabólitos secundários, in: C.M.O. Simões, E.P. Schenkel, G. Gosmann, J.C.P. Mello, P.R. Petrovick (orgs.). Farmacognosia: da planta ao medicamento. Editora UFRGS: Porto Alegre, Editora UFSC, Florianópolis, 2010, pp. 403-434.

Schelkle B, Snellgrove D, Jones LL, Cable J. 2015. Efficacy of commercially available products against Gyrodactylus turnbulli infections on guppies Poecilia reticulata. Dis Aquat Org 115: 129137.

Sharifi-Rad J, Sureda A, Tenore GC, Daglia M, Sharifi-Rad M, Valussi M, Tundis R, Sharifi-Rad M, Loizzo MR, Ademiluyi AO, Sharifi-Rad R, Ayatollahi SA, Iriti M. 2017. Biological activities of essential oils: from plant chemoecology to traditional healing systems. Molecules 22: 70. DOI:10.3390/molecules22010070.

Shinn AJ, Pratoomyot J, Bron J, Paladini G, Brooker E, Brooker A. 2015. Economic impacts of aquatic parasites on global finfish production. Global Aqua Advocate 58-61.

Soares BV, Tavares-Dias M. 2013. Espécies de Lippia (Verbenaceae), seu potencial bioativo e importância na medicina veterinária e aquicultura. Biota Amaz 3: 109-123.

Soares BV, Neves LR, Oliveira MSB, Chaves FCM, Dias MKR, Chagas EC, Tavares-Dias M. 2016. Antiparasitic activity of the essential oil of Lippia alba on ectoparasites of Colossoma macropomum (tambaqui) and its physiological and histopathological effects. Aquaculture 452: 107-114.

Soares BV, Neves LR, Ferreira DO, Oliveira MSB, Chaves FCM, Chagas EC, Gonçalves RA, Tavares-Dias M. 2017a. Antiparasitic activity, histopathology and physiology of Colossoma macropomum (tambaqui) exposed to the essential oil of Lippia sidoides (Verbenaceae). Vet Parasitol 234: 49-56.

Soares BV, Cardoso ACF, Campos RR, Gonçalves BB, Santos GG, Chaves FCM, Chagas EC, Tavares-Dias M. 2017b. Antiparasitic, physiological and histological effects of the essential oil of Lippia origanoides (Verbenaceae) in native freshwater fish Colossoma macropomum. Aquaculture 469: 72-78.

Soler-Jiménez LC, Paredes-Trujillo AI, Vidal-Martínez VM. 2017. Helminth parasites of finfish commercial aquaculture in Latin America. J Helminthol 91: 110-136.

Steverding D, Morgan E, Tkaczynski P, Walder F, Tinsley R. 2005. Effect of Australian tea tree oil on Gyrodactylus spp. infection of the three-spined stickleback Gasterosteus aculeatus. Dis Aquat Org 66: 29-32.

Stroh J, Wan MT, Isman MB, Moul DJ. 1998. Evaluation of the acute toxicity to juvenile Pacific Coho salmon and rainbow trout of some plant essential oils, a formulated product, and the carrier. Bull Environ Contam Toxicol 60: 923-930.

Sutili FJ, Gressler LT, Baldisserotto B. 2014. Anthelmintic activity of the phytochemical eugenol against the fish parasite Gyrodactylus sp. and acute toxicity in Daphnia pulex. Panamjas 9: 223-227.

Tak JH, Isman MB. 2015. Enhanced cuticular penetration as the mechanism for synergy of insecticidal constituents of rosemary essential oil in Trichoplusia ni. Sci Rep 5: 12690. DOI:10.1038/ srep12690.

Valero A, Romero MC, Gómez-Mateos M, Hierro I, Navarro MC. 2015. Natural products: perspectives in the pharmacological treatment of gastrointestinal anisakiasis. APJTM 8: 612-617.

Valladão GMR, Gallani SU, Ikefuti CV, Cruz C, Levy-Pereira N, Rodrigues MVN, Pilarski F. 2016. Essential oils to control ichthyophthiriasis in pacu, Piaractus mesopotamicus (Holmberg): special emphasis on treatment with Melaleuca alternifolia. J Fish Dis 39: 1143-52.

Velisek J, Svobodova Z, Piackova V, Groch L, Nepejchalova L. 2005. Effects of clove oil anesthesia on common carp (Cyprinus carpio L.). Vet Med 50: 269-275.

Vidal LVO, Furuya WM, Graciano TS, Schamber CR, Santos LD, Soares CM. 2007. Concentrações de Eugenol para anestesia profunda e toxidade aguda em juvenis de piavuçu (Leporinus macrocephalus). Acta Sci Biol Sci 29: 357-362.

Vidal LVO, Albinati RCB, Albinati-Luscher AC, Lira AD, Almeida TR, Santos GB. 2008. Eugenol como anestésico para a tilápia-donilo. Pesqui Agropecu Bras 43: 1069-1074.

Cite this article as: Tavares-Dias M. 2018. Current knowledge on use of essential oils as alternative treatment against fish parasites. Aquat. Living Resour. 31: 13 